\title{
Medical evacuation on high seas
}

\author{
Ajit C. Kulkarni
}

Medical Centre, Mumbai, India

\begin{abstract}
A previously healthy Indian male seafarer aged 34 years, presented with vague perianal symptoms to the Master on a Very Large Crude Carrier (VLCC) in the Pacific Ocean. Over a few days, his condition deteriorated, and the company's medical consultant ashore, based on telephonic consultation, transmitted information and photos, diagnosed the condition as a life threatening case of Fournier's gangrene. The ship was then almost $1140 \mathrm{~nm}$ from the port. The consultant instructed the Master to intensify antibiotic treatment and started necessary procedures for an urgent complex medevac. Arranged by the United States Coast Guard, it involved deployment of two helicopters, two fixed wing aircrafts and an air tanker. Helicopters needed to be refuelled mid-air to increase their range of operations. Rendezvous point was $478 \mathrm{~nm}$ from Santa Barbara, California. 31/2 hours after lift off from the vessel, the helicopter landed at Santa Barbara airport and the patient was transported to hospital. State-of-the-art treatment ashore preserved both testicles and after long term recovery the seafarer was again fit for ship duty.
\end{abstract}

(Int Marit Health 2019; 70, 4: 216-219)

Key words: medical aid to ships, helicopter evacuation, Fournier's gangrene

\section{INTRODUCTION}

Every occupation has its own associated hazards, so does seafaring. Apart from occupational hazards of work on board, being away from medical treatment adds to the seriousness of the situation. Ships carry essential medicines as recommended by International Maritime Organisation (IMO) [1] and Flag state [2]. All crew are required to undergo medical training according to IMO Standards of Training, Certification and Watch-keeping (STCW) Convention [3]. But even the Master, who has more advanced training because he/she is responsible for all medical care aboard, is not really competent to handle serious medical emergencies at sea. All such cases need to be landed ashore for expert treatment. During an emergency, when the ship is still far away from port, complex medical evacuation needs to be carried out by a helicopter.

\section{CASE REPORT}

The patient was a 34-year-old healthy Indian seaman. No previous history of diabetes mellitus, hypertension. Serological tests for human immunodeficiency virus (HIV) and hepatitis $B$ negative. He had been sailing for the past few months on board a Marshall Island Flag, Very Large Crude
Carrier (VLCC), 333 m in length, 299,235 dead weight tonnage (dwt). Current voyage was from Singapore to Long Beach, California, USA. The vessel had an operational speed of 12 knots and a maximum speed of 15 knots. Expected date of arrival at Long Beach was 6 December 2018. The vessel had a total crew of 29 including the Master, 27 Indian and 2 Indonesian nationals.

On 17 November 2018, he complained of pain and burning around anal area after defecation. No bleeding per rectum. No constipation. According to company's rules about illnesses and injuries amongst crew aboard, the Master, contacted company's medical consultant for advice regarding management of the condition. The vessel was at position $3232.2 \mathrm{~N} / 15250 \mathrm{E}$, Distance to Go (DTG) $4754 \mathrm{~nm}$. The consultant recommended the following: stool softening medication available on board and high fibre diet to avoid constipation; avoid straining for stools; anaesthetic ointment for local application; ibuprofen 400 mg tablets for pain relief if necessary.

On 21 November the vessel reported that the patient had developed multiple external piles. He complained of feverish feeling, exhaustion and was unable to work. He also complained of pain in right gluteal region. He was

Dr. Ajit C. Kulkarni, Medical Centre, 3 A, Siddhi Vinayak Chambers, Opp. Mig Cricket Club, Bandra East, Mumbai 400051, India, tel/fax: + 91 26423428/26417143, e-mail: drackulkarni@gmail.com 


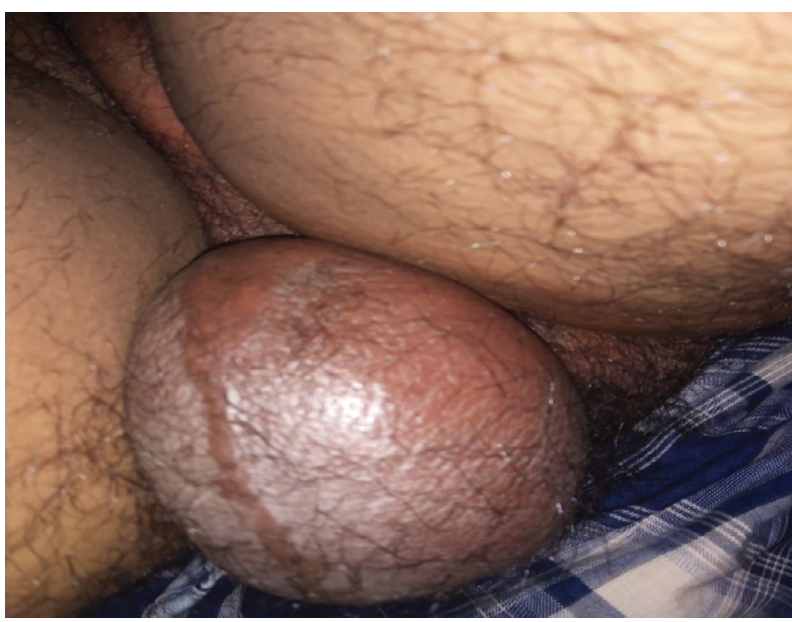

Figure 1. Swollen scrotal contents referred to as "hydrocoele" by the Master

prescribed by consultant Ampicillin $500 \mathrm{mg}$ twice daily. On 26 November, the Master contacted and reported that the patient had developed a swelling of the scrotal contents on right side (which he described as "hydrocoele", Fig. 1) that increased in size rapidly over next 2 days.

On 29 November, at 10:40 local time / GMT-9 (the vessel was at position, $3022.40 \mathrm{~N} / 13841.45 \mathrm{~N}$, DTG $1142 \mathrm{~nm}$ ), the Master reported that some discharge was oozing out of the scrotum and the antibiotic was changed to Amoxicillin $875 \mathrm{mg}+$ Clavulanic acid $125 \mathrm{mg}$ to cover both Gram positive and negative bacterial infection. The patient had difficulty getting up, even to go to the rest room, and a condom drainage system was prepared and connected to a urine collecting bottle. Swelling and redness over right thigh was reported. Urine output, although not measured, was very small in quantity, darkly coloured. Photos received at frequent intervals from the vessel revealed the patient to be toxic, scrotum appeared oedematous, skin chocolate brown in colour indicating gangrenous state. Skin over right thigh was red and inflamed. Infection appeared to have spread up to right mid-thigh level. Provisional diagnosis of Fournier's gangrene was made. Photos were shared with a senior consultant surgeon who concurred with the diagnosis (Fig. 2). Injection Cefuroxime $750 \mathrm{mg}$ was available on board and was prescribed twice daily, deep intramuscularly. Method of preparation of the injection fluid and administration was explained to the Master who was told to read the relevant pages from the International Medical Guide for Ships [4]. The Master and his mates managed to execute this without any difficulty.

The medical consultant feared that that the patient might die unless he was rushed to a hospital for surgical intervention. Vessel operators / charterer had to be convinced about the urgency of situation and that course correction

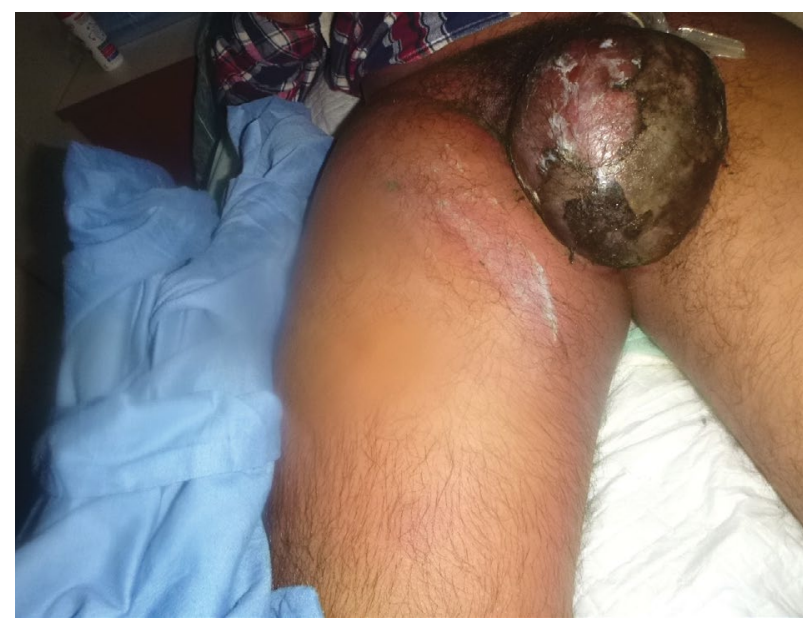

Figure 2. Necrotised scrotal skin and evidence of inflammation on right upper thigh

and increased speed may be required to evacuate the sick crew member. This was agreed to immediately, which helped make further decision making. Rescue Coordination Centre, Alameda, USA, was impressed upon about the emergency situation. Landing permits and immigration formalities were completed post-haste by the local agents.

On 30 November, around 18:00 local time / GMT-8 (the vessel was at $3026.8 \mathrm{~N} / 12837.9 \mathrm{~W}$, DTG $668 \mathrm{~nm}$ ), the Master reported that there was foul odour around the scrotal area, pulse 104 per min, blood pressure 106 / 74 measured digitally. He was advised to gently clean the area with weak solution of polyvidone

In the meanwhile, the Rescue Coordination Centre, Alameda, USA had carried out assessment of situation and assets available. In view of the distance from land, suitable helicopters available for such a long distance evacuation were sourced. Two Black Hawk (HH 60) helicopters with two paramedics in each and two fixed wing C-130 aircrafts were to be used for medevac. Based on the speed of the VLCC, medical evacuation was planned on $1^{\text {st }}$ December around 13:00 PST. Rendezvous position selected, $3026.45 \mathrm{~N}$ and $127.512 \mathrm{~W}$, was $478 \mathrm{~nm}$ from Santa Barbara, California, USA (Fig. 3).

Sequence of medical evacuation events on 1 December 2018 as reported by the Master is as follows:

- 12:28: C-130, Aircraft, designated call sign Rescue 07 called the vessel on VHF channel 16 for safety briefing. Rendezvous point was changed due to operational delay of the helicopters

- 12:30: Commenced safety briefing on VHF channel 16

- 12:42: Completed safety briefing

- 12:50: Helicopter landing checklist completed

- 12:55: Aircraft Rescue 07 informed approaching towards the vessel and making round above the vessel 


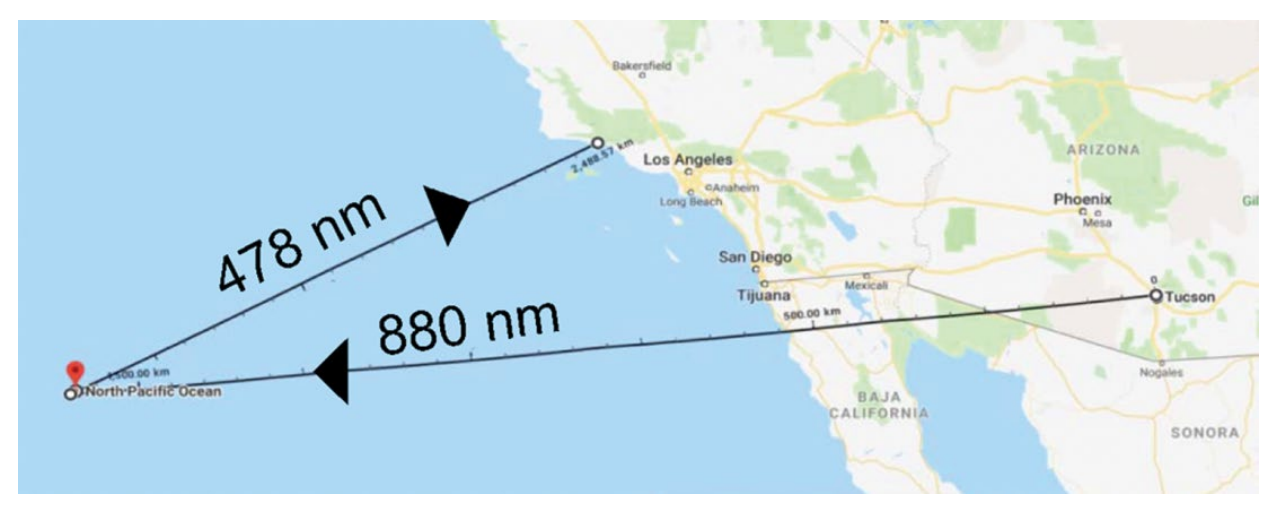

Figure 3. Helicopter route from Davis-Monthan Air Force Base, Tucson, Arizona to the vessel and to Santa Barbara

- 13:00: Aircraft Rescue 07 advised the vessel to alter course 270 and speed 10 knots, as two helicopters, designated call signs Rescue 09 and Rescue 02, were coming shortly to evacuate the patient

- 13:15: Both helicopters started making rounds around the vessel

- 13:18: Helicopter Rescue 09 came to landing area on the vessel and two paramedics were winched down on board the vessel

- 13:20: Helicopter Rescue 02 came to landing area on the vessel and two paramedics with stretcher were inched down

- 13:30: Two injections were given, one on each arm (no details available)

- 13:45: The patient on deck in a stretcher

- 13:56: The patient picked up by helicopter Rescue 02 by winching along with two paramedics and away

- 14:00: Helicopter Rescue 09 came to landing area on the vessel and picked up two paramedics by winching Helicopters landed at Santa Barbara airport, California, USA at 17:30 PST and the patient was taken to Santa Barbara Cottage Hospital for surgical treatment.

Emergency Room assessment revealed following areas of concern in this critically ill patient:

- acute respiratory failure with hypoxia;

- adult respiratory distress syndrome;

- septic shock;

- acute anaemia;

- acute kidney injury;

- ischiorectal abscess;

- necrotizing soft tissue infection.

There was extensive necrotizing fasciitis of the entire scrotum extending into the right inguinal area, groin, proximal right thigh, buttocks and ischiorectal space. There was active drainage of pus from the perirectal region on the right side of perineum. Additionally, there was some drainage from the right scrotum. The entire scrotum was oedematous and pus-filled, with most of the skin black due to necrosis.
During surgical intervention, there appeared to be good blood flow to the cord on right side as well as blood flow to corporal bodies. Superficial tissue surrounding the penis - almost $90 \%$ circumferentially - was necrotic. There was a small skin island to the base of the penis skin. Deeply, tissue appeared viable. Tunica vaginalis surrounding the left testicle appeared necrotic. Both testicles appeared viable with blood flow to tunica albuginea. Both cords and testicles were preserved and placed in a pouch created above pubis.

Colostomy was done to prevent faecal contamination of the wound.

The patient underwent a number of surgical interventions and remained in Intensive Care Unit for extended period of time. Five weeks after admission the patient was uneventfully evacuated by air on stretcher to Mumbai (Bombay), India where he was hospitalised for further treatment, including skin graft procedures and colostomy closure.

He remained in hospital for over 6 weeks. He was followed-up for 2 weeks thereafter and advised physiotherapy. He has since been declared physically fit to resume work.

\section{DISCUSSION}

Medical aid to a seriously ill or injured sailor on high seas is always a problem. Means for communication with shore has improved tremendously over the past few years. Real time information can be exchanged with doctors ashore but in case of serious medical situation the crew is helpless not being competent to implement instructions. In such situations, means of evacuation and distance from port with medical facilities play a major role.

Very Large Crude Carriers, by their sheer size, do not go alongside in any port and casualty evacuation is always a challenge. It has to be carried out by a boat or in case of emergency situation by using a helicopter. VLCCs often receive pilot and stores on board from helicopters. Helicopter landing area is marked on the deck and the crew is well versed in helicopter landing procedure [5]. 
Pre-employment medical examination plays an essential role in selecting healthy crew. Those joining VLCCs need special consideration as voyages are long and there is no "port stay". Those with pre-existing diseases need additional evaluation and assessment by a specialist. If the medical condition recurs, it cannot be investigated and treated on board before becoming life threatening, telemedicine notwithstanding. Persons with past medical history of peptic ulcer, obstructive lung disorders (COPD), prostatic hypertrophy, irritable bowel (IBS) etc. do not become unfit to undertake long voyages at sea but the risk of serious recurrence arising at sea needs to be assessed in each case so also the contingency plan for rapid intervention ready, should a problem arise. Such a seafarer could be considered for employment on a coastal or near coastal voyage where, in case of an emergency, crew can reach onshore medical facility within a short time.

It must also be remembered that shipping companies, charterers, are often reluctant to deviate from course and speed due to commercial reasons.

Fournier gangrene is a specific form of necrotizing fasciitis, localised on the external genital organs, as well as in the perineal region, accompanied by thrombosis of the feeding arteries, leading to gangrene of the skin and subcutaneous tissue, with manifestations of severe septicaemia and multiple organ failure. This is an extremely rare disease that occurs in 1.6 cases per 100,000 men per year, amounting to $0.02-0.90 \%$ of total admissions to the surgical hospital. Average age of the patient is 50.9 years and the ratio of men to women is 10:1. This disease often appears in immuno-compromised patients with diabetes, obesity, and malignant neoplasms. The basic treatment of Fournier gangrene includes an extensive emergency surgical intervention combined with antibiotic therapy to control septicaemia. Prognosis is directly related to the timing of medical care. Treatment delay is accompanied by a high lethality, reaching $90 \%$, due to development of septic shock and its associated complications. Testes are not affected because of their independent blood supply. Testicular artery arises from the abdominal aorta just below the renal artery and then entering the spermatic cord [6].

Very Large Crude Carrier had an operational speed of 12 knots and a top speed of 15 knots. There is an exponential increase in fuel consumption when speed is increased and could be about US \$2-3000 per day over and above calculated fuel cost which the charterers would have to bear. Even if the VLCC could sustain continuous top speed, theoretically only 72 additional $\mathrm{nm}$ could be covered every day, $360 \mathrm{~nm}$ instead of $288 \mathrm{~nm}$. Medevac may have been less complex if the vessel could reach a port, but once septicaemia sets in, how the body reacts and the outcome cannot be predicted. Whether the patient could have survived an extra day or two on board is beyond comprehension. Additionally, a weekend was approaching when things move at a slow pace. Death on board would have had severe psychological impact on the rest of the crew, so also to the ship owners, managers, charterers, in fact, everyone connected to the VLCC.

Decision to evacuate was appropriate under the circumstances and shipowners, ship operator, charterer and all others supported the medical evacuation whole heartedly. Regional Coordination Centre Alameda, USA played a yeoman service, utilising all available resources on a war footing. Black Hawk (HH 60) helicopters were to be launched from Davis-Monthan Air Force Base, Tucson, Arizona at 0630 PST. One of the fixed wing C-130 was to be overhead the VLCC for Command and Control and coordinate the operations. Second C-130 aircraft ensured 100 per cent redundancy in the event of an emergency on board one of the aircraft, the other aircraft would already be on scene and able to conduct an immediate rescue. Both were carrying extra rescue personnel including gear such as Rescue crafts that can be deployed for the rescuers to use. Helicopters were fitted with a special mid-air refuelling rig allowing them to receive fuel and continue flying en-route to rendezvous location. Refuelling air tanker provided fuel to both helicopters. Pilots of the helicopters flew almost $880 \mathrm{~nm}$ for 7 hours to reach the rendezvous point and then another $3 \frac{1}{2} 2$ hours to Santa Barbara airport. Planning and execution of this mammoth operation is truly commendable.

This wholehearted support saved a life!

\section{REFERENCES}

1. International Medical Guide for Ships. 3rd Edition, World Health Organization. 2007. ISBN 9789241547208 Chapter 33 pages 430-453.

2. Republic of Marshall Islands, Maritime Administrator; Marine Notice No 7-042-1, Rev Jan / 2018.

3. International Maritime Organization: Section A-VI/4, STCW conference .2/34, 3 August 2010.

4. International Medical Guide for Ships. 3rd Edition, World Health Organization. 2007. ISBN 9789241547208 pages 325-326.

5. International Medical Guide for Ships. 3rd Edition, World Health Organization. 2007. ISBN 9789241547208 pages 293-295.

6. Chernyadyev SA, Ufimtseva MA, Vishnevskaya IF, et al. Fournier's Gangrene: Literature Review and Clinical Cases. Urol Int. 2018; 101(1): 91-97, doi: 10.1159/000490108, indexed in Pubmed: 29949811. 